Research Article

\title{
Comparison between Whatman FTA Elute Cards and Conventional Swab for the Detection of Pathogenic Enteric Bacteria Using an RT-qPCR Assay
}

\author{
Na Yue $\mathbb{D}$ and Zichao Jia \\ Department of Clinical Laboratory, Tianjin Medical University General Hospital, Tianjin 300070, China \\ Correspondence should be addressed to Na Yue; yuena19800304@163.com
}

Received 6 March 2021; Accepted 25 June 2021; Published 2 July 2021

Academic Editor: Louis Detolla

Copyright (c) $2021 \mathrm{Na}$ Yue and Zichao Jia. This is an open access article distributed under the Creative Commons Attribution License, which permits unrestricted use, distribution, and reproduction in any medium, provided the original work is properly cited.

\begin{abstract}
The emergence of outbreaks of foodborne illness is closely associated with food contamination caused by various enteric pathogens, such as Escherichia coli O157:H7, Listeria monocytogenes, Salmonella enterica serovar Enteritidis, and Staphylococcus aureus. The control of enteric pathogens poses a challenge due to the fact that these pathogens can persist for a long period of time in the environment. The rapid detection of pathogenic organisms plays a crucial role in the prevention and identification of crises related to health, safety, and well-being. Improper sample handling and processing may influence the diagnostic efficacy and accuracy. The aim of the present study was to compare the preservation capacity for enteric bacteria between Whatman Flinders Technology Associates (FTA) cards and swabs for reverse transcription-quantitative PCR (RT-qPCR) detection. It was found that Whatman FTA cards exhibited an improved preservation capacity for five types (both laboratory and environmental strains) of enteric bacteria, including Escherichia coli O157:H7, Listeria monocytogenes, Salmonella enterica serovar Enteritidis, and Staphylococcus aureus for RT-qPCR detection. Hence, Whatman FTA cards may be a suitable tool for the routine isolation of foodborne bacteria for molecular diagnosis. Therefore, the use of Whatman FTA cards for sample collection and preservation may increase sensitivity and accuracy for bacteria isolation and diagnosis.
\end{abstract}

\section{Introduction}

The human intestinal microbiome plays an important role in maintaining health and preventing disease in the body [1]. The emergence of outbreaks of foodborne illness is closely related to food contamination caused by various enteric pathogens, which has been reported to cause high morbidity and mortality among humans worldwide [2]. The World Health Organization (WHO) reported that there were approximately a few million cases of foodborne illness caused by pathogenic bacteria each year [3]. The control of enteric pathogens poses a challenge, as these pathogens can persist for a long period of time in the environment [2].

There are few common enteric bacteria, including Escherichia coli O157:H7, Listeria monocytogenes, Salmonella enterica serovar Enteritidis, and Staphylococcus aureus [4]. These bacterial pathogens have been reported to often cause foodborne diseases and hospitalization among humans [5, 6]. Escherichia coli O157:H7 was first discovered in 1982 in Oregon and Michigan as a causative reagent for food contamination, which could cause serious illness, including abdominal pain, watery diarrhea, and hemorrhagic colitis [7]. As a foodborne pathogen, Listeria monocytogenes causes severe fatal gastrointestinal illness and is associated with a high mortality rate (i.e., 24\%) [8]. Salmonella enterica serovar Enteritidis is an important Gram-negative intracellular pathogen with a broad host range, whose characteristic is that the pathogen can induce salmonellosis in humans and animals [9]. Staphylococcus aureus is a Grampositive opportunistic pathogen, which is an important nosocomial pathogen [10]. Staphylococcus aureus has been reported to infect multiple tissues, including the intestine, skin, soft tissue, and lung [11]. The aforementioned four 
enteric pathogens pose a heavy burden to public health worldwide; thus, attention should be paid to their hazardous effects.

The rapid detection of pathogenic organisms plays a crucial role in prevention and identification of crises related to health, safety, and wellbeing [12]. It is challenging to diagnose pathogenic bacteria at very early stage due to the lack of sensitive detection methods [13]. Several diagnostic methods have been developed for the detection of bacteria, including PCR [14], filter paper method [15], sensor systems [16], and the Scan system method [17]. Among these methods, PCR is one of the most commonly used detection approaches, which was developed towards the end of the last century and is broadly used in the biology and medicine fields [17]. PCR is a relatively rapid detection method for bacterial identification, which normally requires between 5 and $24 \mathrm{~h} \mathrm{[18].} \mathrm{However,} \mathrm{improper} \mathrm{sample} \mathrm{handling} \mathrm{and}$ processing may influence the diagnostic efficacy and accuracy [19]. Long-term storage and frozen samples may decrease the number of bacteria, which can lead to falsenegative results [20]. Therefore, it is crucial to select an optimal handling method for the detection of bacteria when using PCR assay.

Flinders Technology Associates (FTA) cards were specifically developed to simplify the handling and processing of nucleic acids [21]. An FTA card is comprised of a cottonbased cellulose paper treated with anionic detergents and buffer, which provides a stable matrix for the immobilization of genomes for molecular characterization, but is free from the living host cells or organism [22]. The use of FTA cards for the processing of samples for pathogen identification has been reported [23]. For PCR, a previous study has found that FTA cards can be used to diagnose a number of types of pathogen, including HIV, pathogenic fungi, etc. [24]. However, information regarding the effects of FTA cards on PCR detection is still limited [25]. The present study compared the differences between Whatman ${ }^{\mathrm{TM}}$ FTA Elute cards and conventional swabs for the handling of enteric bacteria, including Escherichia coli O157:H7, Listeria monocytogenes, Salmonella enterica serovar Enteritidis, and Staphylococcus aureus when detected by reverse transcription-quantitative PCR (RT-qPCR) assay. The information presented herein may be helpful for selecting the optimal handling and process method for bacterial diagnosis.

\section{Materials and Methods}

2.1. Reagents. BeyoPure ${ }^{\mathrm{TM}}$ LB Broth (premixed powder, cat. no. ST156, Beyotime Institute of Biotechnology) and BeyoPure $^{\mathrm{TM}}$ LB Broth with Agar (premixed powder) (cat. no. ST158) were purchased from Beyotime Institute of Biotechnology. Whatman FTA Elute cards were obtained from Whatman plc; Cytiva (Whatman WB120315).

2.2. Bacteria. Escherichia coli O157:H7, Listeria monocytogenes, Salmonella enterica serovar Enteritidis, and Staphylococcus aureus were obtained from the Tianjin Medical University General Hospital Bacteria Bank.
Escherichia coli O157:H7 was cultured in Luria-Bertani (LB) medium at $37^{\circ} \mathrm{C}$ with shaking at $180 \mathrm{rpm}$ for $18-24 \mathrm{~h}$. For enumeration, the culture was serially diluted in PBS and plated on LB agar incubated at $37^{\circ} \mathrm{C}$ for a further $22-24 \mathrm{~h}$. Based on the counting results, the sample was serially diluted with deionized water to seven various concentrations $\left(1 \times 10^{7} \mathrm{CFU} / \mathrm{ml}, \quad 5 \times 10^{6} \mathrm{CFU} / \mathrm{ml}, \quad 2.5 \times 10^{5} \mathrm{CFU} / \mathrm{ml}\right.$, $6.25 \times 10^{4} \mathrm{CFU} / \mathrm{ml}, 3.125 \times 10^{4} \mathrm{CFU} / \mathrm{ml}, 3.125 \times 10^{4} \mathrm{CFU} / \mathrm{ml}$, and $7.8125 \times 10^{3} \mathrm{CFU} / \mathrm{ml}$ ). Various concentrations of bacteria were dropped on a Whatman FTA card and swab and stored at $4^{\circ} \mathrm{C}$ for 2 days for use in further experiments.

For Listeria monocytogenes, seed stocks of the bacteria were stored in Listeria enrichment broth (LEB) and $16.7 \%$ glycerol at $-80^{\circ} \mathrm{C}$. To grow the bacteria, $10 \mathrm{ml}$ of sterile LEB was aliquoted into a culture tube, inoculated, and placed in a shaker/incubator overnight at $250 \mathrm{rpm}\left(37^{\circ} \mathrm{C}\right)$. The number of bacteria was counted, and was subsequently serially diluted with deionized water to seven various concentrations $\left(1 \times 10^{7} \mathrm{CFU} / \mathrm{ml}, \quad 5 \times 10^{6} \mathrm{CFU} / \mathrm{ml}, \quad 2.5 \times 10^{5} \mathrm{CFU} / \mathrm{ml}\right.$, $6.25 \times 10^{4} \mathrm{CFU} / \mathrm{ml}, 3.125 \times 10^{4} \mathrm{CFU} / \mathrm{ml}, 3.125 \times 10^{4} \mathrm{CFU} / \mathrm{ml}$, and $7.8125 \times 10^{3} \mathrm{CFU} / \mathrm{ml}$ ). Various concentrations of bacteria were dropped on a Whatman FTA card and swab and stored at $4^{\circ} \mathrm{C}$ for 2 days for use in further experiments.

For Salmonella enterica serovar Enteritidis, one single typical colony was inoculated in $10 \mathrm{ml}$ sterile brain heart infusion (BHI) broth, vortexed, and incubated at $37^{\circ} \mathrm{C}$ overnight $(\sim 16 \mathrm{~h})$, followed by counting the number of bacteria, and was subsequently serially diluted with deionized water to seven various concentrations $\left(1 \times 10^{7} \mathrm{CFU} / \mathrm{ml}\right.$, $5 \times 10^{6} \mathrm{CFU} / \mathrm{ml}, \quad 2.5 \times 10^{5} \mathrm{CFU} / \mathrm{ml}, \quad 6.25 \times 10^{4} \mathrm{CFU} / \mathrm{ml}$, $3.125 \times 10^{4} \mathrm{CFU} / \mathrm{ml}, \quad 3.125 \times 10^{4} \mathrm{CFU} / \mathrm{ml}, \quad$ and $\left.7.8125 \times 10^{3} \mathrm{CFU} / \mathrm{ml}\right)$.

In terms of Staphylococcus aureus, a single colony of bacteria was incubated in $10 \mathrm{ml}$ Tryptone Soy Broth with $0.3 \%$ Yeast Extract (TSB-YE) at $37^{\circ} \mathrm{C}$ overnight with shaking at $190 \mathrm{rpm}$, followed by counting the number of bacteria, and was subsequently serially diluted with deionized water to seven various concentrations $\left(1 \times 10^{7} \mathrm{CFU} / \mathrm{ml}\right.$, $5 \times 10^{6} \mathrm{CFU} / \mathrm{ml}, \quad 2.5 \times 10^{5} \mathrm{CFU} / \mathrm{ml}, \quad 6.25 \times 10^{4} \mathrm{CFU} / \mathrm{ml}$, $3.125 \times 10^{4} \mathrm{CFU} / \mathrm{ml}, \quad 3.125 \times 10^{4} \mathrm{CFU} / \mathrm{ml}, \quad$ and $\left.7.8125 \times 10^{3} \mathrm{CFU} / \mathrm{ml}\right)$. All bacterial samples were stored at $4^{\circ} \mathrm{C}$ for use in following experiments.

2.3. Food Sample Sampling Process Using Whatman FTA Elute Cards and Swabs. Food samples containing Escherichia coli O157:H7, Listeria monocytogenes, Salmonella enterica serovar Enteritidis, and Staphylococcus aureus were obtained from the bio-sample bank of Tianjin Medical University General Hospital. Pathogens in food samples were diagnosed prior to storage in the bio-sample bank. Food samples were cut into sections, followed by being diluted with $1 \mathrm{ml}$ sterile water, and filtered. The filtrate was dropped on Whatman FTA cards and swabs and stored at $4^{\circ} \mathrm{C}$ for 2 days for further experiments, respectively.

2.4. DNA Template Preparation. Crude DNA was isolated from bacterial samples on the FTA cards and swabs. DNA isolation was performed using a Genomic DNA Mini 
Preparation kit with Spin Colum (cat. no. D0063Beyotime Institute of Biotechnology) according to the manufacturer's instructions. Briefly, bacteria on the FTA cards and swabs were eluted with $180 \mu$ l lysis buffer A, followed by the addition of $20 \mu \mathrm{l}$ proteinase $\mathrm{K}$, and incubation in a water bath $\left(37^{\circ} \mathrm{C}\right)$ for $10 \mathrm{~min}$. Subsequently, the samples were supplemented with $200 \mu \mathrm{l}$ lysis buffer B, followed by the addition of $200 \mu \mathrm{l}$ ethanol, and were completely mixed. The samples were then added to the DNA purification spin column, followed by spinning down at $>6,000 \times \mathrm{g}$. Subsequently, spin columns with DNA were washed with wash buffer I and II, followed by spinning down at $>18,000 \times \mathrm{g}$ to dry the filter of the spin column. DNA was eluted with $50 \mu \mathrm{l}$ elution buffer for use in further experiments.

2.5. RT-qPCR. RT-qPCR was performed using the iCycler iQ real-time detection system (Bio-Rad Laboratories, Inc.) according to manufacturer's instructions. Briefly, a bacterium DNA $(2 \mu \mathrm{l})$ was added to a hot-start reaction mixture containing SYBR-Green mix (BeyoFast ${ }^{\mathrm{TM}}$ SYBR-Green qPCR Mix; cat. no. D7260, Beyotime Institute of Biotechnology) and primers (Table 1). The program of RT-qPCR included an initial step of $95^{\circ} \mathrm{C}$ for $10 \mathrm{~min}$ followed by an amplification program for 40 cycles of $3 \mathrm{sec}$ at $95^{\circ} \mathrm{C}, 5 \mathrm{sec}$ at $61^{\circ} \mathrm{C}$, and $20 \mathrm{sec}$ at $72^{\circ} \mathrm{C}$ with fluorescence acquisition at the end of each extension. Subsequently, a melt program consists of $60 \mathrm{sec}$ at $95^{\circ} \mathrm{C}, 60 \mathrm{sec}$ at $65^{\circ} \mathrm{C}$, and a gradual increase to $90^{\circ} \mathrm{C}$ at a rate of $0.2^{\circ} \mathrm{C} / \mathrm{sec}$ with fluorescence acquisition at each temperature transition. The genes, including stx 1 and stx2, were measured for Escherichia coli O157:H7, as that these two genes are two major virulence factors and often used for the diagnosis of Escherichia coli O157:H7 [26]. HlyA164 and hlyA177 are commonly used for the diagnosis of Listeria monocytogenes [27]. InvA, as one of the major virulence genes of Salmonella enterica serovar Enteritidis, is often used for the detection of this bacteria [28]. FemB is one of the genes encoding proteins which influences the level of methicillin resistance of Staphylococcus aureus, and it is often used for the detection of Staphylococcus aureus [29].

2.6. Statistical Analysis. The data were processed using GraphPad Prism (v8.0.2.263). One-way ANOVA followed by the Bonferroni test was applied to verify significant differences between groups. Differences with $P<0.05$ were considered to indicate a statistically significant difference.

\section{Results}

3.1. CT Value of Escherichia coli O157:H7 Genes in Whatman FTA Elute Cards Is Higher than in Swabs. To compare the ability to preserve bacterial samples between Whatman Elute FTA cards and conventional swabs (Figure 1), $200 \mu \mathrm{l}$ Escherichia coli O157:H7 was added on a Whatman Elute FTA card and conventional swab, followed by the detection of the expression of the stx 1 and stx 2 genes. It was found that the CT values of the stx1 gene of Escherichia coli O157:H7 on the Whatman Elute FTA card were significantly lower than those on the conventional swab (Figures 2(a) and 2(b), $n=6$;
$P<0.05, P<0.01$, and $P<0.001)$. Similarly, it was found that the CT values of the stx 2 gene of Escherichia coli O157:H7 on the Whatman Elute FTA card were significantly lower than those on the conventional swab (Figures 2(c) and 2(d), $n=6$; $P<0.05, P<0.01$, and $P<0.001)$. Thus, it was confirmed that the preservation capacity to Escherichia coli O157:H7 of the Whatman Elute FTA card was better than that of the conventional swabs.

To further determine the difference in the capacity for bacterial preservation between the Whatman Elute FTA card and conventional swabs, food samples containing Escherichia coli O157:H7 were collected with the Whatman Elute FTA card and conventional swabs. After $48 \mathrm{~h}$, the expression of stx 1 and stx 2 was examined by RT-qPCR. It was found that the CT values of the stx1 and stx2 gene of Escherichia coli $\mathrm{O} 157: \mathrm{H7}$ on the Whatman Elute FTA card were significantly lower than those on the conventional swab for three food samples (Figures 3(a) and 3(b), $n=6 ; P<0.05$ and $P<0.01)$.

3.2. CT Values of Listeria monocytogenes Genes in Whatman FTA Elute Cards Are Higher than Those in Swabs. Listeria monocytogenes is one of main foodborne bacteria; therefore, the difference in the preservation ability of Whatman FTA Elute cards and swabs for Listeria monocytogenes was compared by RT-qPCR assay. It was found that the expression of the Listeria monocytogenes gene, hlyA177, was significantly higher in samples collected using Whatman FTA Elute cards than those collected with swabs (Figures 4(a) and 4(b), $n=5 ; \quad P<0.05, \quad P<0.01$, and $P<0.001)$. Another gene named hlyA164 of Listeria monocytogenes was also detected by RT-qPCR, which indicated that its expression was significantly higher in samples collected using Whatman FTA Elute cards than those collected using swabs (Figures 4(c) and $4(\mathrm{~d}), n=5 ; P<0.05$ and $P<0.01)$.

To further investigate the difference in the capacity for bacterial preservation for Listeria monocytogenes between the Whatman Elute FTA cards and conventional swabs, four food samples containing Listeria monocytogenes contamination were collected using Whatman Elute FTA cards and conventional swabs. After $48 \mathrm{~h}$, the expression of stx 1 and stx2 was examined by RT-qPCR. It was indicated that the CT values of the hlyA177 and hlyA164 genes of Listeria monocytogenes on the Whatman Elute FTA card were significantly lower than those on the conventional swab for three food samples (Figures 5(a) and 5(b), $n=6 ; P<0.05$ and $P<0.01)$.

3.3. CT Values of the Salmonella enterica Serovar Enteritidis Gene in Whatman FTA Elute Cards Are Higher than Those on Swabs. Salmonella enterica serovar Enteritidis is another main foodborne pathogen. Thus, the difference in the preservation ability for Salmonella enterica serovar Enteritidis of Whatman FTA Elute cards and swabs was compared by RT-qPCR assay. It was found that the expression of the Salmonella enterica serovar Enteritidis gene, invA, was significantly lower in samples collected using Whatman FTA 
Table 1: Primers used in the study.

\begin{tabular}{|c|c|c|c|c|}
\hline Bacteria & Gene name & & Sequence $\left(5^{\prime}-3^{\prime}\right)$ & $\begin{array}{l}\text { Amplicon size } \\
\text { expected (bp) }\end{array}$ \\
\hline \multirow{6}{*}{ Escherichia coli O157:H7 } & & Forward & TTTGTYACTGTSACAGCWGAAGCYTTACG & \multirow{3}{*}{132} \\
\hline & Shiga toxins (stx1) & Reverse & CCCCAGTTCARWGTRAGRTCMACRTC & \\
\hline & & Probe-FAM & CTGGATGATCTCAGTGGGCGTTCTTATGTA A & \\
\hline & \multirow{3}{*}{ Shiga toxins (stx2) } & Forward & TTTGTYACTGTSACAGCWGAAGCYTTACG & \multirow{3}{*}{128} \\
\hline & & Reverse & CCCCAGTTCARWGTRAGRTCMACRTC & \\
\hline & & Probe-VIC & TCGTCAGGCACTGTCTGAAACTGCTCC & \\
\hline \multirow{4}{*}{ Listeria monocytogenes } & \multirow{2}{*}{ hlyA-177 } & hlyA-177-F & TGCAAGTCCTAAGACGCCA & \multirow{2}{*}{120} \\
\hline & & hlyA-177-R & CACTGCATCTCCGTGGTATACTAA & \\
\hline & \multirow{2}{*}{ hlyA-146 } & hlyA-146-F & AAATCTGTCTCAGGYGATGT & \multirow{2}{*}{113} \\
\hline & & hlyA-146-R & CGATGATTTGAACTTCATCTTTTGC & \\
\hline \multirow{2}{*}{ Salmonella enteritidis } & \multirow{2}{*}{ invA } & invA-F & CACGCTCTTTCGTCTGGCA & \multirow{2}{*}{154} \\
\hline & & invA-R & TACGGTTCCTTTGACGGTGCGA & \\
\hline \multirow{2}{*}{ Staphylococcus aureus } & \multirow{2}{*}{ FemB } & FemB-F & AATTAACGAAATGGGCAGAAACA & \multirow{2}{*}{93} \\
\hline & & FemB-R & TGCGCAACACCCTGAACTT & \\
\hline
\end{tabular}

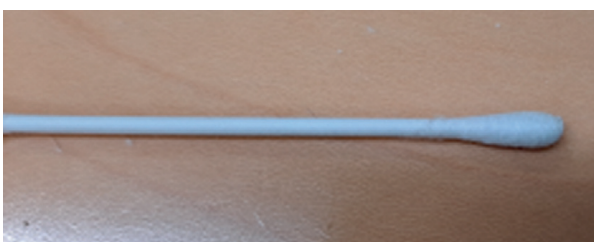

(a)

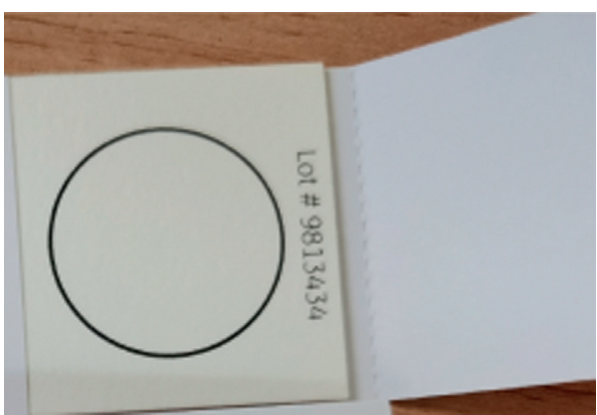

(b)

FIgURE 1: Conventional swab and Whatman FTA card.

Elute cards than in those collected using swabs (Figures 6(a) and $6(\mathrm{~b}), n=5 ; P<0.05$ and $P<0.01)$. To further examine the difference in the capacity for bacterial preservation for Salmonella enterica serovar Enteritidis between Whatman Elute FTA card and conventional swabs, three food samples containing Salmonella enterica serovar Enteritidis contamination were collected using Whatman Elute FTA cards and conventional swabs. After $48 \mathrm{~h}$, the expression of the invA was examined by RT-qPCR. It was indicated that the CT values of invA of Salmonella enterica serovar Enteritidis on Whatman Elute FTA cards were significantly lower than those on conventional swabs for the three food samples (Figure 6(c), $n=6 ; P<0.05$ and $P<0.01$ ).

3.4. CT Values of the Staphylococcus aureus Gene in Whatman FTA Elute Cards Are Higher than Those in Swabs. Staphylococcus aureus can cause severe food poisoning, and the diagnosis of the pathogen remains challenging in food or the environment [25]. Thus, the present study compared the difference in the preservation ability for Staphylococcus aureus of Whatman FTA Elute cards and swabs by RT-qPCR assay. It was found that expression of the Staphylococcus aureus gene, FemB, was significantly higher in samples collected using Whatman FTA Elute cards than those collected using swabs (Figures 7 (a) and 7(b), $n=6 ; P<0.05$, $P<0.01$, and $P<0.001)$. To further examine the difference in the capacity for bacterial preservation for Staphylococcus aureus between Whatman Elute FTA cards and conventional swabs, three food samples containing Staphylococcus aureus contamination were collected using Whatman Elute FTA cards and conventional swabs. After $48 \mathrm{~h}$, the expression of the FemB gene was examined bu RT-qPCR. It was indicated that the CT values of FemB of Staphylococcus aureus on Whatman Elute FTA cards were significantly lower than those on conventional swabs for the three food samples (Figure $7(\mathrm{c}), n=6 ; P<0.05$ and $P<0.01$ ).

\section{Discussion}

Foodborne disease outbreak remains a major challenge for public health worldwide [30]. Enteric bacteria, such as Escherichia coli O157:H7, Listeria monocytogenes, Salmonella enterica serovar Enteritidis, and Staphylococcus aureus, are considered as main pathogens which cause foodborne disease [7]. Accurate and rapid diagnosis plays a crucial in the prevention of infections from these enteric pathogens. The present study compared the differences in the 


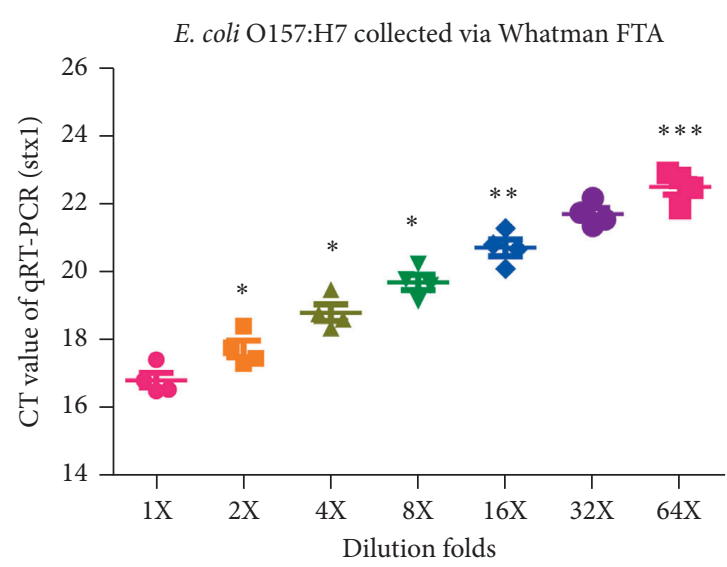

(a)

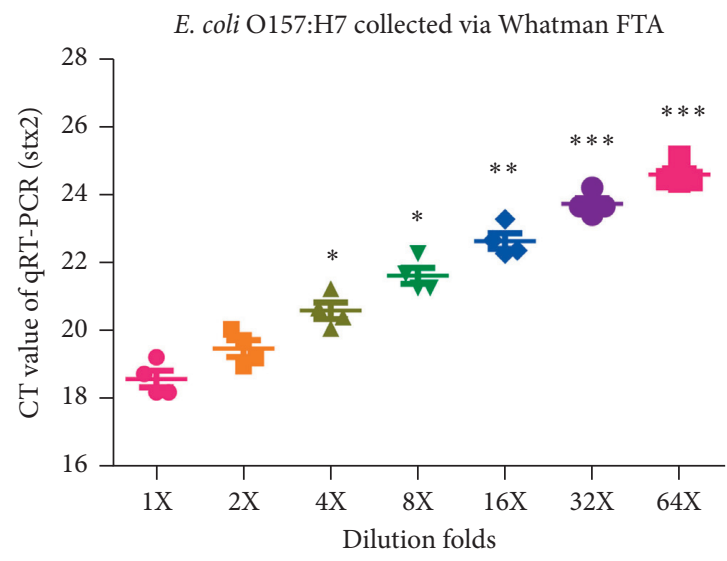

(c)

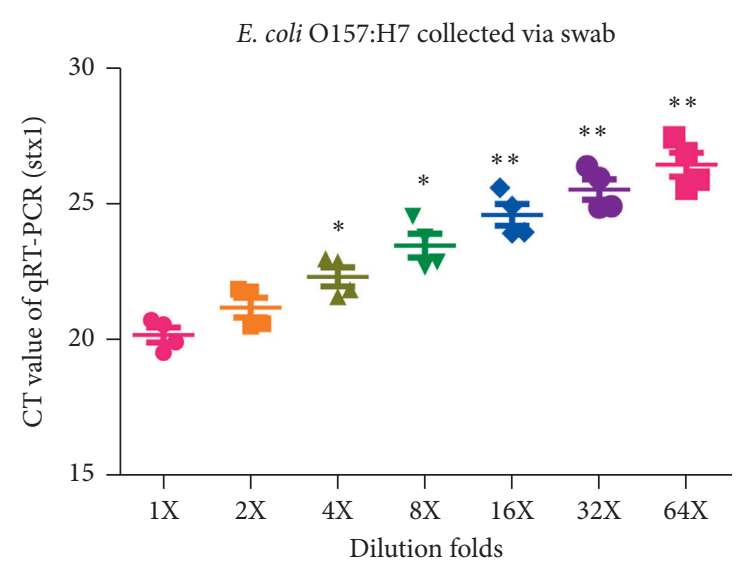

(b)

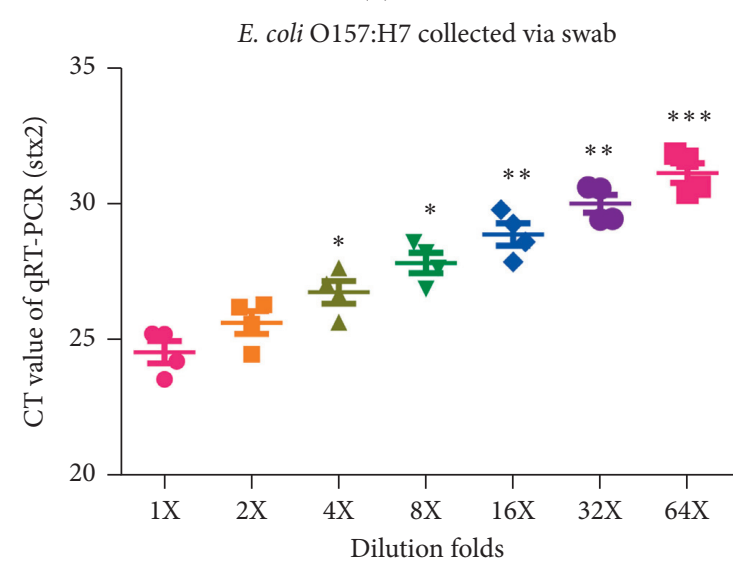

(d)

Figure 2: CT values of Escherichia coli O157:H7 genes in samples on Whatman FTA elute cards are higher than those on swabs. (a) Expression level of the stx1 gene in a serially diluted laboratory strain of Escherichia coli O157:H7 samples on Whatman FTA cards detected by RT-qPCR $\left(n=6,{ }^{*} P<0.05,{ }^{* *} P<0.01\right.$, and $\left.{ }^{* * *} P<0.001\right)$. (b) Expression level of the stx1 gene in a serially diluted laboratory strain of Escherichia coli O157:H7 samples on swabs detected by RT-qPCR $\left(n=6,{ }^{*} P<0.05\right.$ and $\left.{ }^{* *} P<0.01\right)$. (c) Expression level of the stx2 gene in a serially diluted laboratory strain of Escherichia coli O157:H7 samples on Whatman FTA cards detected by RT-qPCR $\left(n=6,{ }^{*} P<0.05\right.$, ${ }^{* *} P<0.01$, and $\left.{ }^{* * *} P<0.001\right)$. (d) Expression level of the stx2 gene in a serially diluted laboratory strain of Escherichia coli O157:H7 samples on swabs detected by RT-qPCR $\left(n=6,{ }^{*} P<0.05,{ }^{* *} P<0.01\right.$, and $\left.{ }^{* * *} P<0.001\right)$. RT-qPCR: reverse transcription-quantitative PCR; FTA: Flinders Technology Associates.

preservation ability of Whatman FTA Elute cards and swabs for Escherichia coli O157:H7, Listeria monocytogenes, Salmonella enterica serovar Enteritidis, and Staphylococcus aureus by RT-qPCR assay. It was found that Whatman FTA Elute cards had a stronger preservation capacity for these five enteric bacteria compared with conventional swabs. Thus, it was confirmed that Whatman FTA Elute cards may be a suitable tool for collecting samples of Escherichia coli O157:H7, Listeria monocytogenes, Salmonella enterica serovar Enteritidis, and Staphylococcus aureus when diagnosis is made by RT-qPCR assay. The information presented herein may prove to be useful for the diagnosis and prevention of infections from enteric bacteria.

Collection, sample storage, and bacterial DNA extraction methods play an important role in accurately detecting intestinal bacteria [31]. Swab collection is one of the most commonly used methods for the isolation and/or detection of bacteria using molecular methods [32]. However, the storage temperature and storage duration will influence the isolation and molecular detection of bacteria [33]. Although the swab collection method has been used for viral or bacterial collection for decades, some disadvantages have been reported including the following: (i) the swab market can be disorderly and includes a large number of manufacturers without production licenses; (ii) swabs containing fresh samples of highly pathogenic microorganisms still have infection risks; (iii) swabs are easily contaminated. Therefore, an improved sample collection method is required compared with swabs for pathogenic bacterial isolation for detection by the molecular method.

FTA matrix cards developed by Whatman have been demonstrated to be suitable for the rapid collection, purification, and analysis of genetic material from a wide range of biological sources, such as whole blood, buccal scrapes, tissues, plasmids, plant material, and microorganisms [34]. Whatman FTA cards have been used for the isolation of a 


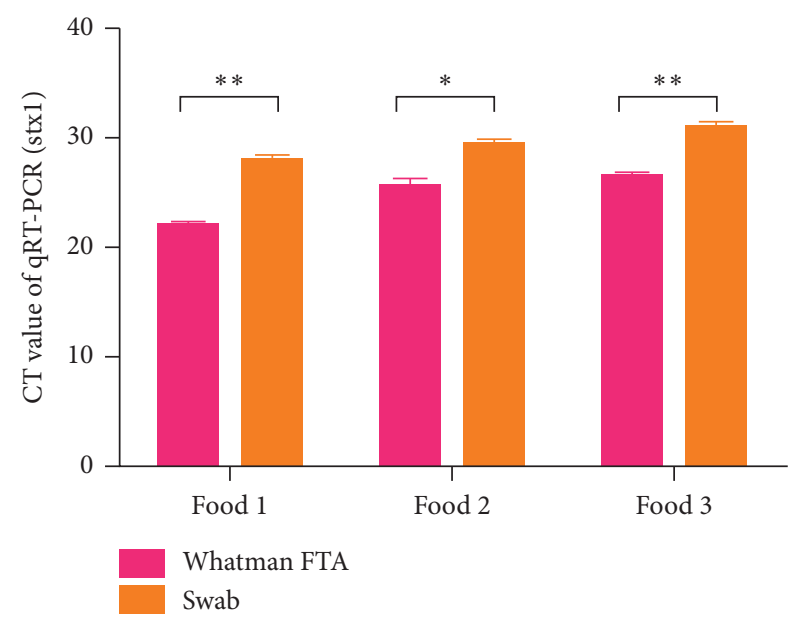

(a)

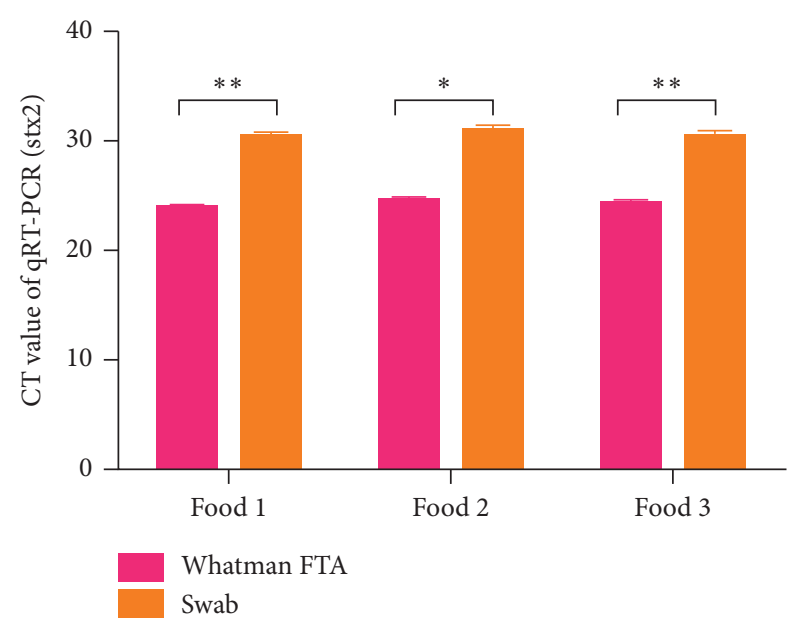

(b)

FIGURE 3: Detection of Escherichia coli O157:H7 genes in food samples containing Escherichia coli O157:H7 contamination by RT-qPCR collected using Whatman FTA cards and swabs. (a) Expression level of the stx1 gene in a serially diluted environmental strain of Escherichia coli O157:H7 samples on Whatman FTA cards and swabs detected by RT-qPCR $\left(n=6,{ }^{*} P<0.05\right.$ and $\left.{ }^{* *} P<0.01\right)$. (b) Expression level of the stx2 gene in an environmental strain of Escherichia coli O157:H7 samples on Whatman FTA cards and swabs detected by RT-qPCR $(n=6$, $\left.{ }^{* *} P<0.01\right)$. RT-qPCR: reverse transcription-quantitative PCR; FTA: Flinders Technology Associates.

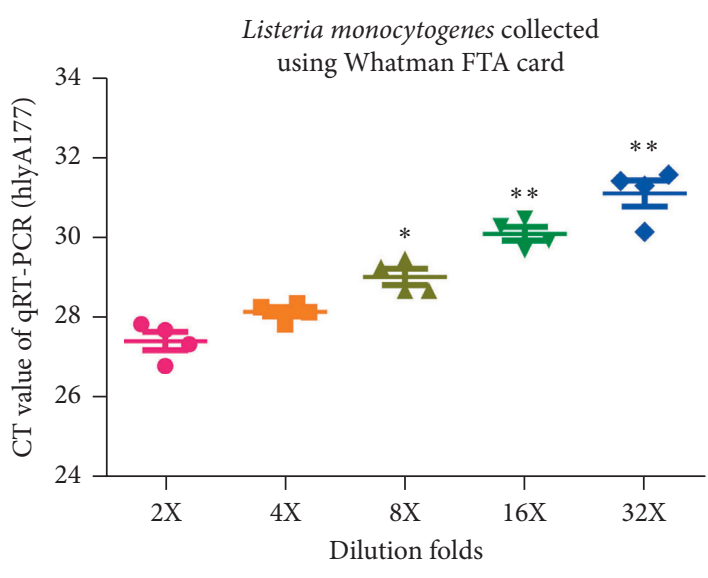

(a)

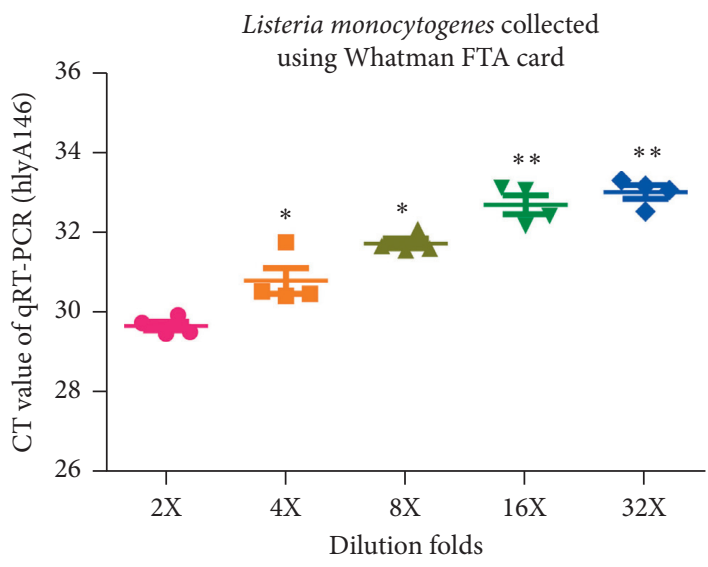

(c)

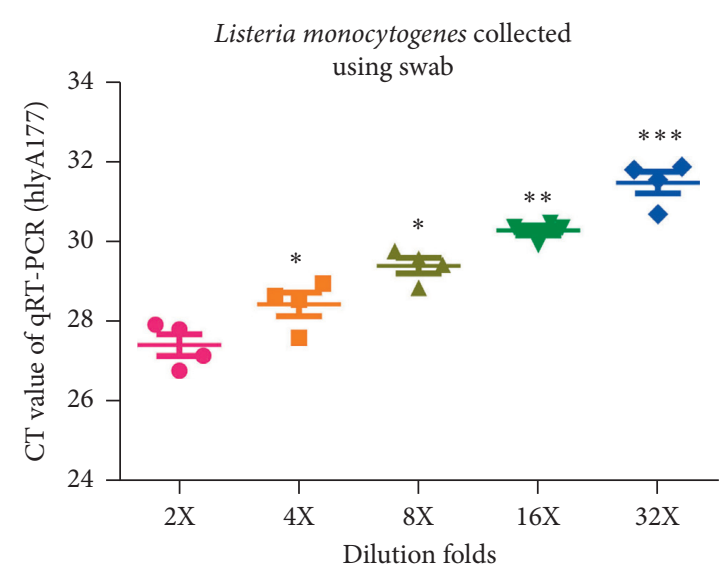

(b)

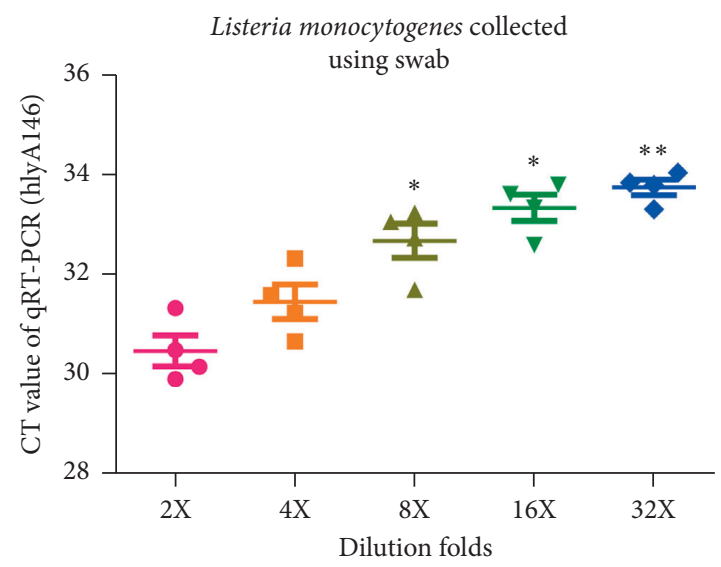

(d)

FIgURE 4: CT values of Listeria monocytogenes genes in samples on Whatman FTA Elute cards are higher than those on swabs. (a) Expression level of the hly177 gene in a serially diluted laboratory strain of Listeria monocytogenes samples on Whatman FTA cards detected by RTqPCR $\left(n=6,{ }^{*} P<0.05\right.$ and $\left.{ }^{* *} P<0.01\right)$. (b) Expression level of the hly177 gene in a serially diluted laboratory strain of Listeria monocytogenes samples on swabs detected by RT-qPCR $\left(n=6,{ }^{*} P<0.05\right.$ and $\left.{ }^{* *} P<0.01\right)$. (c) Expression level of the hly146 gene in a serially diluted laboratory strain of Listeria monocytogenes samples on Whatman FTA cards detected by RT-qPCR $\left(n=6,{ }^{*} P<0.05\right.$, ${ }^{* *} P<0.01$, and $\left.{ }^{* * *} P<0.001\right)$. (d) Expression level of the hly146 gene in a serially diluted laboratory strain of Listeria monocytogenes samples on swabs detected by RT-qPCR $\left(n=6,{ }^{*} P<0.05,{ }^{* *} P<0.01\right.$, and $\left.{ }^{* * *} P<0.001\right)$. RT-qPCR: reverse transcription-quantitative PCR; FTA: Flinders Technology Associates. 


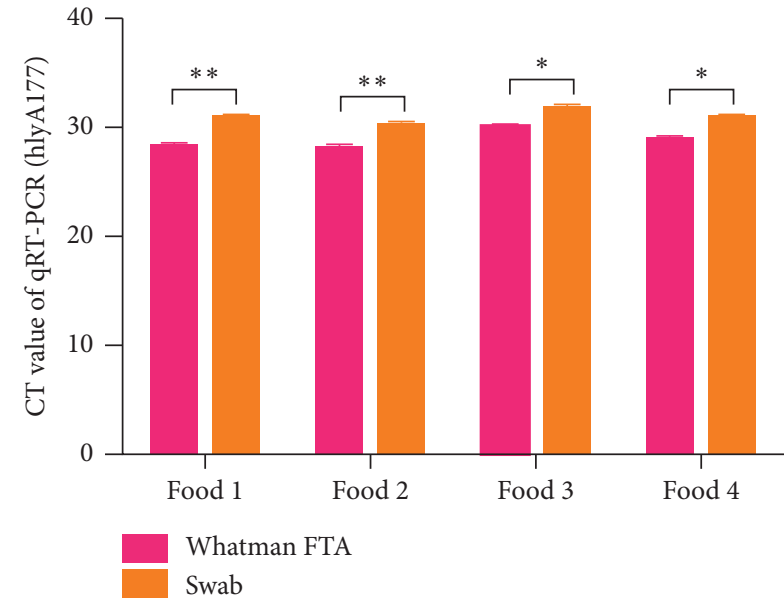

(a)

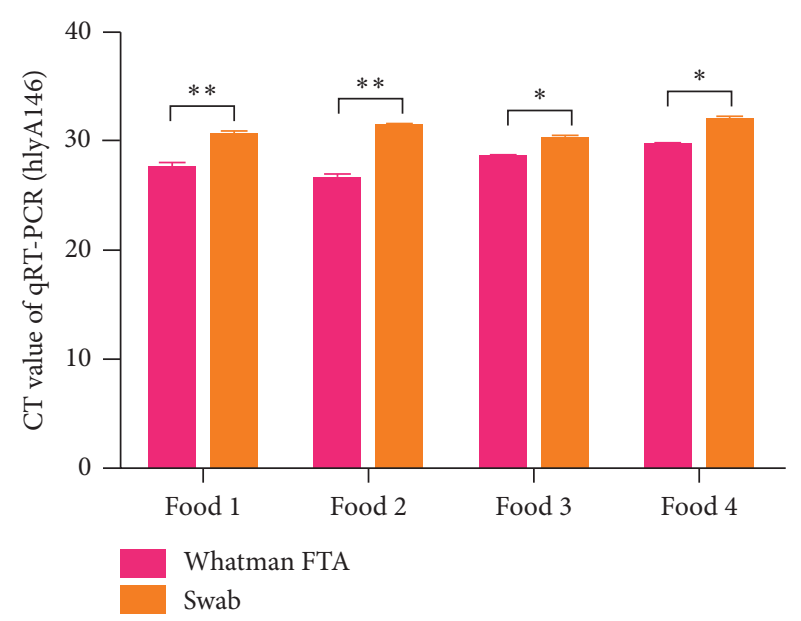

(b)

FIGURE 5: Detection of Listeria monocytogenes genes in food samples containing Listeria monocytogenes contamination by RT-qPCR collected using Whatman FTA cards and swabs. (a) Expression level of the hly177 gene in a serially diluted environmental strain of Listeria monocytogenes samples on Whatman FTA cards and swabs and detected by RT-qPCR $\left(n=6,{ }^{*} P<0.05\right.$ and $\left.{ }^{* *} P<0.01\right)$. (b) Expression level of the hly146 gene in an environmental strain of Listeria monocytogenes samples on Whatman FTA cards and swabs detected by qRT-PCR $\left(n=6,{ }^{*} P<0.05\right.$ and $\left.{ }^{* *} P<0.01\right)$. RT-qPCR: reverse transcription-quantitative PCR; FTA: Flinders Technology Associates.

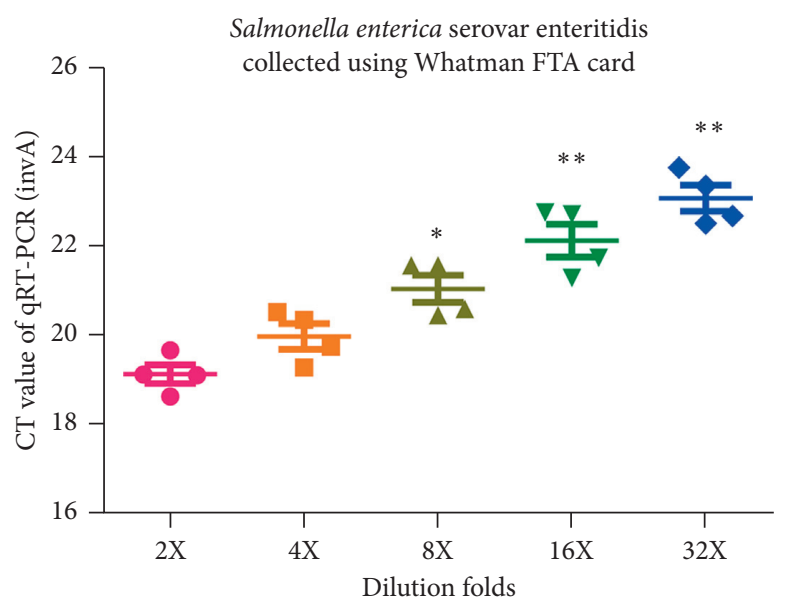

(a)

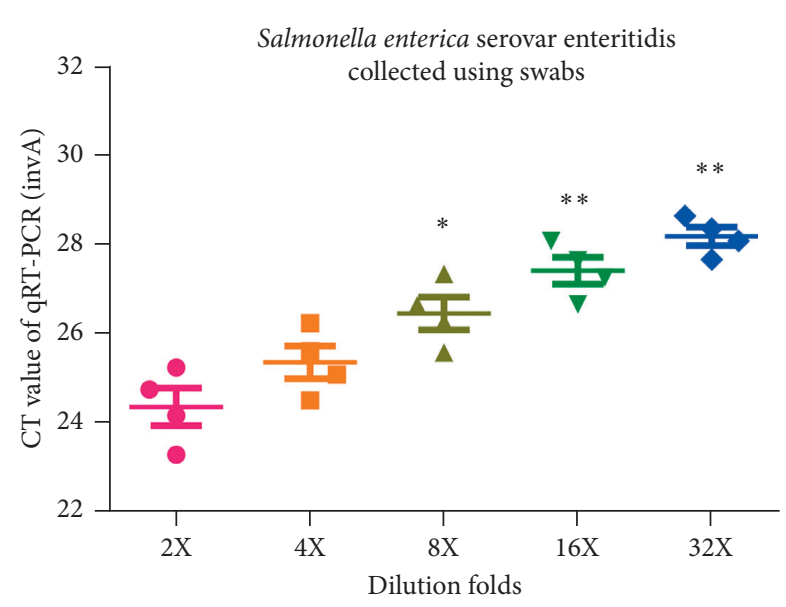

(b)

FIgURE 6: Continued. 


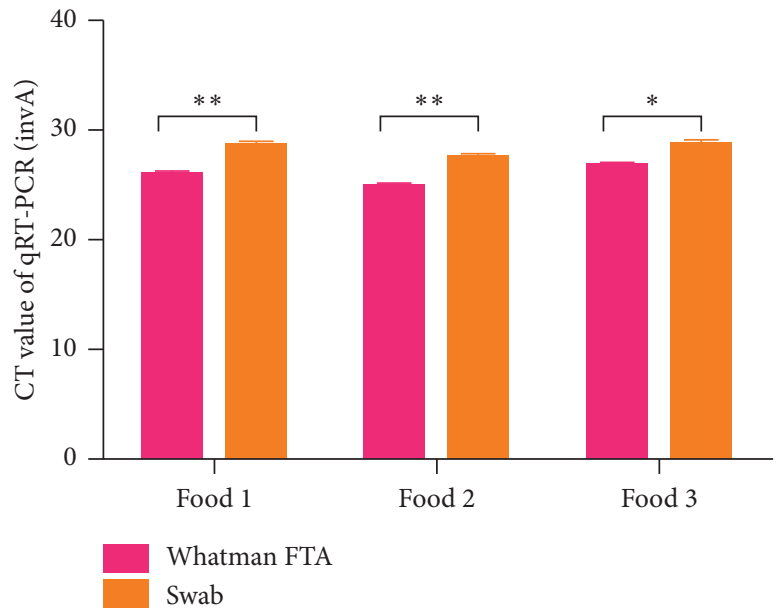

(c)

FIgURE 6: CT values of the Salmonella enterica serovar Enteritidis gene in Whatman FTA Elute cards are higher than those on swabs. (a) Expression of the Salmonella enterica serovar Enteritidis gene invA in samples collected using Whatman FTA Elute cards detected by RTqPCR $\left(n=6,{ }^{*} P<0.05\right.$ and $\left.{ }^{* *} P<0.01\right)$. (b) Expression of the Salmonella enterica serovar Enteritidis gene invA in samples collected using swabs detected by RT-qPCR $\left(n=6,{ }^{*} P<0.05\right.$ and $\left.{ }^{* *} P<0.01\right)$. (c) Expression level of the invA gene in an environmental strain of Salmonella enterica serovar Enteritidis samples on Whatman FTA cards and swabs detected by RT-qPCR $\left(n=6,{ }^{*} P<0.05\right.$ and $\left.{ }^{* *} P<0.01\right)$. RT-qPCR: reverse transcription-quantitative PCR; FTA: Flinders Technology Associates.

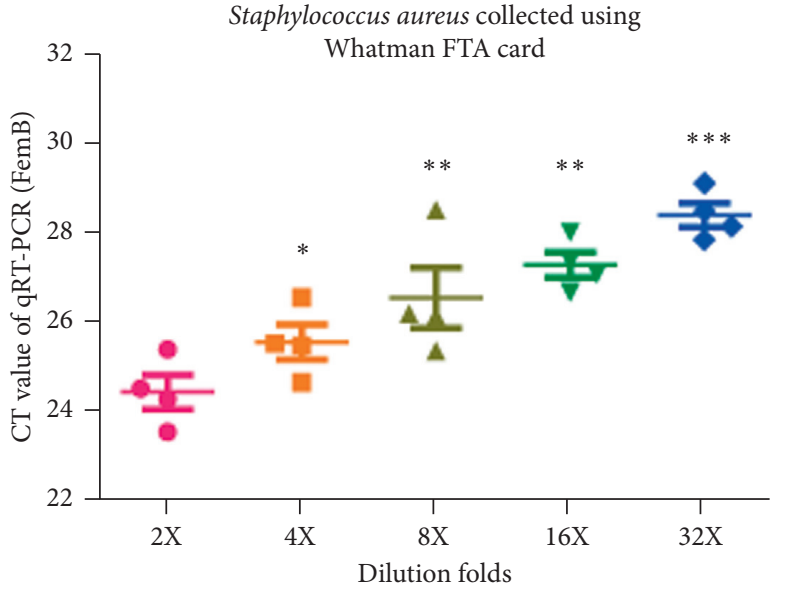

(a)

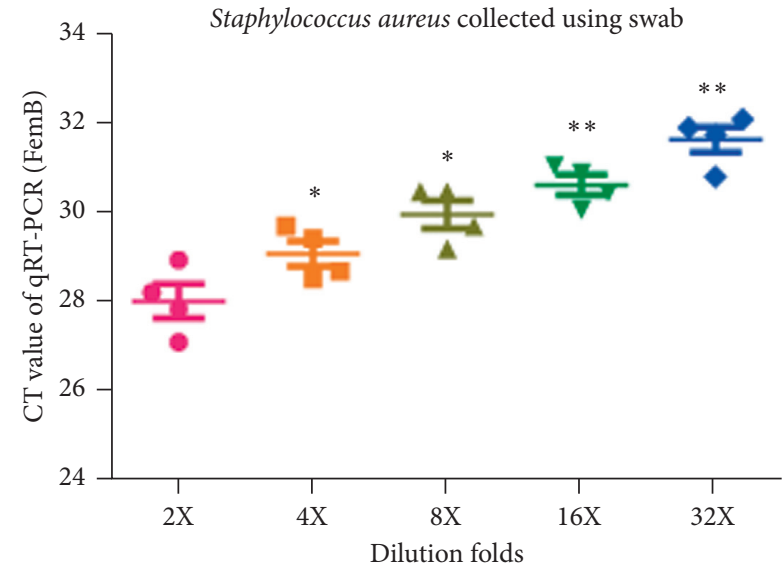

(b)

Figure 7: Continued. 


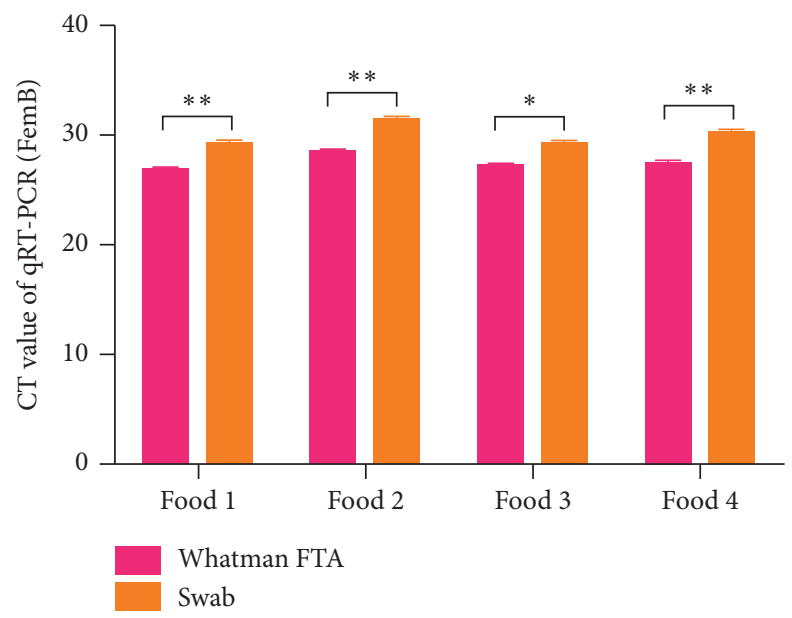

(c)

Figure 7: CT values of the Staphylococcus aureus gene in Whatman FTA Elute cards are higher than those on swabs. (a) Expression of the Staphylococcus aureus gene FemB in samples collected using Whatman FTA Elute cards detected by RT-qPCR $\left(n=6,{ }^{*} P<0.05\right.$, ${ }^{* *} P<0.01$, and $\left.{ }^{* * *} P<0.001\right)$. (b) Expression of the Staphylococcus aureus gene FemB in samples collected using swabs detected by RT-qPCR $(n=6$, ${ }^{*} P<0.05$ and ${ }^{* *} P<0.01$ ). (c) Expression level of the FemB gene in an environmental strain of Staphylococcus aureus samples on Whatman FTA cards and swabs detected by RT-qPCR $\left(n=6,{ }^{*} P<0.05\right.$ and $\left.{ }^{* *} P<0.01\right)$. RT-qPCR: reverse transcription-quantitative PCR; FTA: Flinders Technology Associates.

variety of pathogens, including viruses, bacteria, and fungus for molecular detection [35]. Several studies have confirmed the advantages of Whatman FTA cards in collecting pathogenic samples. In the study performed by Sierra-Arguello et al. [34], it was found that 100 bacteria samples were successfully amplified using the $16 \mathrm{~S}$ rDNA gene and demonstrated by DNA sequencing following storage for 3 years at an ambient temperature, which manifested the robust preservation capacity for bacteria of FTA cards. Fowler et al. [36] made use of Whatman FTA cards to store DNA for a long period of time, followed by analyzing single nucleotide polymorphism (SNP); they found that DNA could be isolated from all samples of Whatman FTA cards, which indicated the potent ability of FTA cards for DNA storage. In another study, researchers used Whatman $\mathrm{FTA}^{\mathrm{TM}}$ filter paper to collect onion samples containing infections of pathogenic Fusarium oxysporum strains for detection using the PCR method and found that Whatman FTA ${ }^{\mathrm{TM}}$ filter paper exhibited potent preservation ability for Fusarium oxysporum [37]. In the present study, it was found that Whatman FTA cards exhibited a higher preservation capacity to five types (both laboratory and environmental strains) of bacteria, including Escherichia coli O157:H7, Listeria monocytogenes, Salmonella enterica serovar Enteritidis, and Staphylococcus aureus for detection by RT-qPCR. The possible reason that Whatman FTA can store DNA for a longer period of time than conventional methods (e.g., swabs) is that the chemical (e.g., anionic detergents) on the cotton-based cellulose paper has the ability to immobilize genomes of organisms. However, conventional methods do not have this type of chemical and can thus not store DNA for a long period of time [22]. Hence, Whatman FTA cards may be a suitable tool for the routine isolation of foodborne bacteria for molecular diagnosis.
In conclusion, in the present study, it was confirmed that Whatman FTA cards were more suitable for preserving enteric bacteria, such as Escherichia coli O157:H7, Listeria monocytogenes, Salmonella enterica serovar Enteritidis, and Staphylococcus aureus than conventional tools, such as swabs when the RT-qPCR method is used to detect bacteria. Therefore, the use of Whatman FTA cards for sample collection and preservation may increase the sensitivity and accuracy for bacterial isolation and diagnosis.

\section{Data Availability}

All the original data used to support the findings of this study may be released upon application to Tianjin Medical University General Hospital, who can be contacted through Na Yue (yuena19800304@163.com).

\section{Conflicts of Interest}

The authors declare that they have no conflicts of interest.

\section{Authors' Contributions}

N. Y. was responsible for study design, data collection and analysis, and manuscript writing and editing; Z. J. was responsible for experiments, data collection and analysis, and manuscript draft writing.

\section{References}

[1] S. V. Lynch and O. Pedersen, "The human intestinal microbiome in health and disease," New England Journal of Medicine, vol. 375, no. 24, pp. 2369-2379, 2016.

[2] M. T. Brandl, "Fitness of human enteric pathogens on plants and implications for food safety," Annual Review of Phytopathology, vol. 44, no. 1, pp. 367-392, 2006. 
[3] A. H. Havelaar, M. D. Kirk, P. R. Torgerson et al., "World health organization global estimates and regional comparisons of the burden of foodborne disease in 2010," PLoS Medicine, vol. 12, no. 12, Article ID e1001923, 2015.

[4] A. Chlebicz and K. Śliżewska, "Campylobacteriosis, salmonellosis, yersiniosis, and listeriosis as zoonotic foodborne diseases: a review," International Journal of Environmental Research and Public Health, vol. 15, no. 5, p. 863, 2018.

[5] Y. Inatsu, M. L. Bari, S. Kawasaki, and K. Isshiki, "Survival of Escherichia coli O157:H7, Salmonella enteritidis, Staphylococcus aureus, and Listeria monocytogenes in Kimchi," Journal of Food Protection, vol. 67, no. 7, pp. 1497-1500, 2004.

[6] Y. Yin and D. Zhou, "Organoid and enteroid modeling of Salmonella infection," Frontiers in Cellular and Infection Microbiology, vol. 8, p. 102, 2018.

[7] P. Elizaquível and R. Aznar, "A multiplex RTi-PCR reaction for simultaneous detection of Escherichia coli O157:H7, Salmonella spp. and Staphylococcus aureus on fresh, minimally processed vegetables," Food Microbiology, vol. 25, no. 5, pp. 705-713, 2008.

[8] V. Braga, S. Vázquez, V. Vico et al., "Prevalence and serotype distribution of Listeria monocytogenes isolated from foods in Montevideo-Uruguay," Brazilian Journal of Microbiology, vol. 48, no. 4, pp. 689-694, 2017.

[9] X. Wei, L. You, D. Wang, H. Huang, S. Li, and D. Wang, "Antimicrobial resistance and molecular genotyping of Salmonella enterica serovar Enteritidis clinical isolates from Guizhou province of Southwestern China," PLoS One, vol. 14, no. 9, Article ID e0221492, 2019.

[10] J. Mehraj, W. Witte, M. K. Akmatov, F. Layer, G. Werner, and G. Krause, "Epidemiology of Staphylococcus aureus nasal carriage patterns in the community," Current Topics in Microbiology and Immunology, vol. 398, pp. 55-87, 2016.

[11] S. Y. C. Tong, J. S. Davis, E. Eichenberger, T. L. Holland, and V. G. Fowler, "Staphylococcus aureus infections: epidemiology, pathophysiology, clinical manifestations, and management," Clinical Microbiology Reviews, vol. 28, no. 3, pp. 603-661, 2015.

[12] H. Tsuji and K. Nomoto, "Yakult intestinal flora-SCAN: a novel culture-independent analytical method for detection of bacteria in the bloodstream," Annals of Nutrition and Metabolism, vol. 71, pp. 4-10, 2017.

[13] L. Wagner, L. Braunschweig, H. Eiffert et al., "Detection of bacteria colonizing titanium spinal implants in children," Surgical Infections, vol. 19, no. 1, pp. 71-77, 2018.

[14] X. P. He, B. J. Zou, X. M. Qi et al., "Methods of isothermal nucleic acid amplification-based microfluidic chips for pathogen microorganism detection," Yi Chuan, vol. 41, pp. 611-624, 2019.

[15] X. H. Zou, Y. P. Zhu, G. Q. Ren et al., "Significance of bacteria detection with filter paper method on diagnosis of diabetic foot wound infection," Zhonghua Shao Shang Za Zhi, vol. 33, pp. 83-88, 2017.

[16] S. M. Yoo and S. Y. Lee, "Optical biosensors for the detection of pathogenic microorganisms," Trends in Biotechnology, vol. 34, no. 1, pp. 7-25, 2016.

[17] S. Ribault, A. Faucon, L. Grave, P. Nannini, and I. B. Faure, "Detection of bacteria in red blood cell concentrates by the Scansystem method," Journal of Clinical Microbiology, vol. 43, no. 5, pp. 2251-2255, 2005.

[18] P. Rajapaksha, A. Elbourne, S. Gangadoo, R. Brown, D. Cozzolino, and J. Chapman, "A review of methods for the detection of pathogenic microorganisms," The Analyst, vol. 144, no. 2, pp. 396-411, 2019.
[19] J. E. Farnsworth, S. M. Goyal, S. Won Kim et al., "Development of a method for bacteria and virus recovery from heating, ventilation, and air conditioning (HVAC) filters," Journal of Environmental Monitoring, vol. 8, no. 10, pp. 1006-1013, 2006.

[20] H. Barth, A. Morel, C. Mougin et al., "Long-term storage and safe retrieval of human papillomavirus DNA using FTA elute cards," Journal of Virological Methods, vol. 229, pp. 60-65, 2016.

[21] F. Awad, M. Baylis, R. C. Jones, and K. Ganapathy, "Evaluation of flinders technology associates cards for storage and molecular detection of avian metapneumoviruses," Avian Pathology, vol. 43, no. 2, pp. 125-129, 2014.

[22] Z. Wang, C. P. Zolnik, Y. Qiu et al., "Comparison of fecal collection methods for microbiome and metabolomics studies," Frontiers in Cellular and Infection Microbiology, vol. 8, p. 301, 2018.

[23] S.-M. Wang, S.-Y. Hu, W. Chen et al., "Feasibility and accuracy evaluation of three human papillomavirus assays for FTA card-based sampling: a pilot study in cervical cancer screening," BMC Cancer, vol. 15, no. 1, p. 848, 2015.

[24] A. M. Borman, C. J. Linton, S. J. Miles, and E. M. Johnson, "Molecular identification of pathogenic fungi," Journal of Antimicrobial Chemotherapy, vol. 61, pp. i7-12, 2008.

[25] T. Lalani, M. D. Tisdale, J. D. Maguire, C. Wongsrichanalai, M. S. Riddle, and D. R. Tribble, "Detection of enteropathogens associated with travelers' diarrhea using a multiplex Luminexbased assay performed on stool samples smeared on Whatman FTA Elute cards," Diagnostic Microbiology and Infectious Disease, vol. 83, no. 1, pp. 18-20, 2015.

[26] A. W. Paton and J. C. Paton, "Detection and characterization of shiga toxigenic Escherichia coli by using multiplex PCR assays for stx1, stx2, eaeA, enterohemorrhagic E. coli hlyA , rfbO111, and rfbO157," Journal of Clinical Microbiology, vol. 36, no. 2, pp. 598-602, 1998.

[27] C. V. Crowther, S. H. Hilton, L. Kemp, and M. A. Hayes, "Isolation and identification of Listeria monocytogenes utilizing DC insulator-based dielectrophoresis," Analytica Chimica Acta, vol. 1068, pp. 41-51, 2019.

[28] R. Heymans, A. Vila, C. A. M. van Heerwaarden et al., "Rapid detection and differentiation of Salmonella species, Salmonella typhimurium and Salmonella enteritidis by multiplex quantitative PCR," PLoS One, vol. 13, no. 10, Article ID e0206316, 2018.

[29] C. Chen, Q. Zhao, J. Guo, Y. Li, and Q. Chen, "Identification of methicillin-resistant Staphylococcus aureus (MRSA) using simultaneous detection of mecA, nuc, and femB by loopmediated isothermal amplification (LAMP)," Current Microbiology, vol. 74, pp. 965-971, 2007.

[30] Y.-W. Tang and C. W. Stratton, "Staphylococcus aureus: an old pathogen with new weapons," Clinics in Laboratory Medicine, vol. 30, no. 1, pp. 179-208, 2010.

[31] S. Chai, W. Gu, K. O'Connor, L. Richardson, and R. Tauxe, "Incubation periods of enteric illnesses in foodborne outbreaks, United States, 1998-2013," Epidemiology \& Infection, vol. 147, 2019.

[32] C. J. Hill, J. R. M. Brown, D. B. Lynch et al., "Effect of room temperature transport vials on DNA quality and phylogenetic composition of faecal microbiota of elderly adults and infants," Microbiome, vol. 4, no. 1, p. 19, 2016.

[33] C. Ball, V. Felice, Y. Ding, A. Forrester, E. Catelli, and K. Ganapathy, "Influences of swab types and storage temperatures on isolation and molecular detection of Mycoplasma gallisepticum and Mycoplasma synoviae," Avian Pathology, vol. 49, no. 1, pp. 106-110, 2020. 
[34] Y. M. Sierra-Arguello, O. Faulkner, G. Tellez, B. M. Hargis, and V. Pinheiro do Nascimento, "The use of FTA cards for transport and detection of gyr A mutation of Campylobacter jejuni from poultry," Poultry Science, vol. 95, no. 4, pp. 798-801, 2016.

[35] D. Rajendram, R. Ayenza, F. M. Holder, B. Moran, T. Long, and H. N. Shah, "Long-term storage and safe retrieval of DNA from microorganisms for molecular analysis using FTA matrix cards," Journal of Microbiological Methods, vol. 67, no. 3, pp. 582-592, 2006.

[36] K. E. Fowler, C. P. Reitter, G. A. Walling, and D. K. Griffin, "Novel approach for deriving genome wide SNP analysis data from archived blood spots," BMC Research Notes, vol. 5, no. 1, p. 503, 2012.

[37] S. Latvala, M. Haapalainen, P. Kivijärvi, T. Suojala-Ahlfors, S. Iivonen, and A. Hannukkala, "Sampling and PCR method for detecting pathogenic Fusarium oxysporum strains in onion harvest," Letters in Applied Microbiology, vol. 70, no. 3, pp. 210-220, 2020. 